\title{
Coffee consumption, bone mineral density and incidence hip fracture in Icelandic community dwelling adults
}

\author{
Professor Alfons Rame \\ Faculty of Food Science and Nutrition, University of Iceland, Reykjavik, Iceland
}

High consumption of coffee has been suggested to reduce the risk of some late-onset diseases and death [1,2] but also to contribute to the development of osteoporotic fractures [3]. Results of previous studies have been inconsistent [4]. The aim of this study was to investigate associations between coffee consumption and bone mineral density (BMD) and hip fracture incidence.

A prospective study of 4831 Icelandic older adults from the AGES-Reykjavik study was conducted. Participants underwent a detailed clinical examination including BMD measurement at baseline (2002-2006). Hip-fracture cases were then identified through hospital records over a mean follow-up of 7.4 years.

Mean age of the participants at baseline was 76.3 years. Frequent coffee consumtion ( $>6$ cups per day) was related to significantly lower BMD at baseline both in men $(-13.2 \pm 5.4 \mathrm{mg} / \mathrm{cm} 3)$ and in women $(-32.2 \pm 5.6 \mathrm{mg} / \mathrm{cm} 3)$ in an age corrected analysis when compared to $\leq 1 \mathrm{cup} /$ day.

Of male participants $5.7 \%$ and of female participants $11.6 \%$ suffered from hip fracture during the follow up period. Coffee consumption was not related to fracture risk in men, but in women, high consumption ( $>6$ cups per day) predicted increased hip fracture risk $(\mathrm{HR}=2.1 ; 95 \% \mathrm{CI}=1.2-4.0 ; \mathrm{P}=0.016)$ when compared to $\leq 1 \mathrm{cup} / \mathrm{day}$. Statistical correction for medication, socioeconomics, nutrition and physical activity did not change the results.

Our study indicates that excessive coffee consumption is associated with poorer BMD in both sexes and predicts incidence hip fracture risk in women.

to the study of nutrition, promotes emerging strategies and their potential impact upon nutritional research.

\section{Acknowledgments}

The original work was funded by the National Institutes of Health, USA contract N01- AG-12100, and the National Institute on Aging Intramural Research Program, the National Eye Institute USA (ZIAEY000401), National Institutes of Health, Hjartavernd (The Icelandic Heart Association), and Althingi (Icelandic Parliament). Work on this study was in part funded by The St.Josef's Hospital Fund, Reykjavik, Iceland, the Landspitali University Hospital Research Fund, the Icelandic Gerontological Society Research Fund, The Helga Jonsdottir and Sigurlidi Kristjánsson Geriatric Research Fund and Fund of Sigridar Larusdottur.

\section{References}

1. Ding M, Bhupathiraju SN, Chen M, et al. (2014) Diabetes Care 37:569-586.

2. Zhang W, Lopez-Garcia E, Li TY, et al. (2009) Diabetes Care 32:1043-1045.

3. Hansen SA, Folsom AR, et al. (2000) Public Health Ntr 23:253-261.

4. Hallström H, Byberg L, et al. (2013) Am. J. Epidemiol 898-909. 